
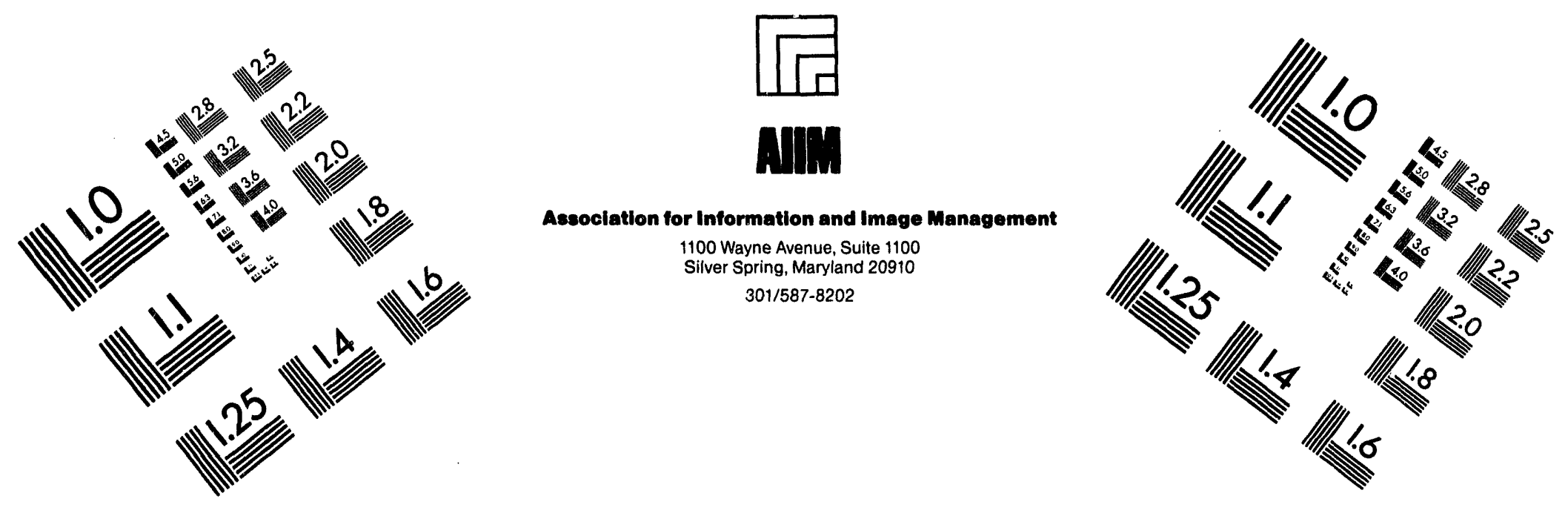

\title{
Centimeter
}

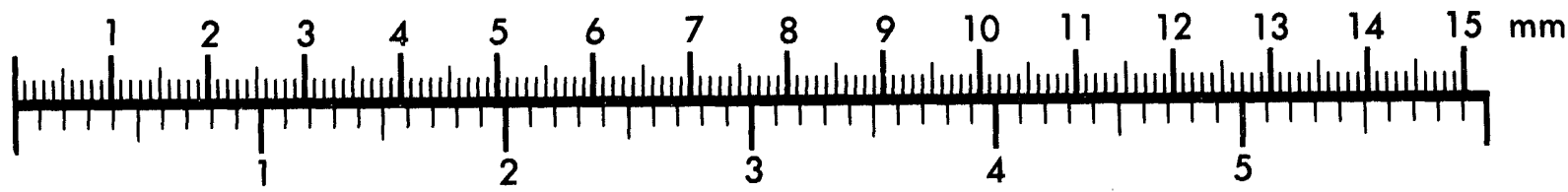
Inches
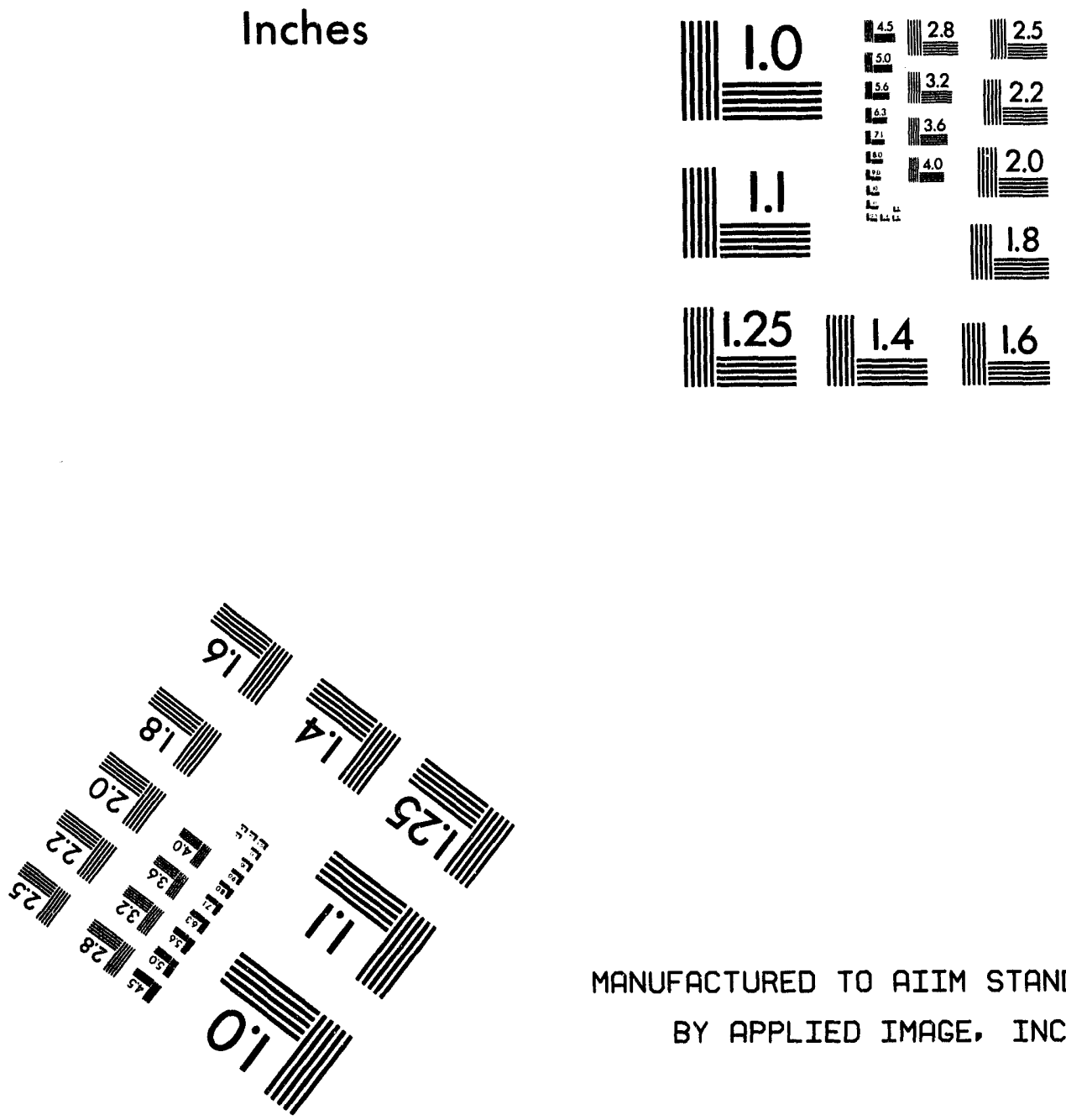

MANUFACTURED TO AIIM STANDARDS BY APPLIED IMAGE, INC.

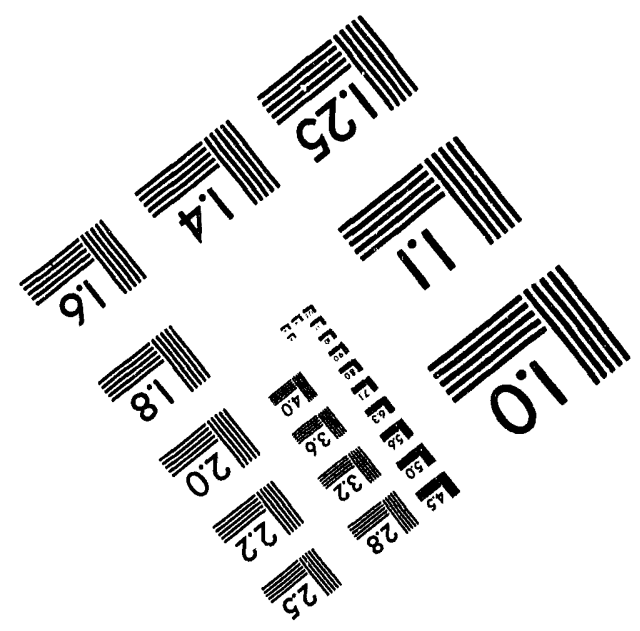



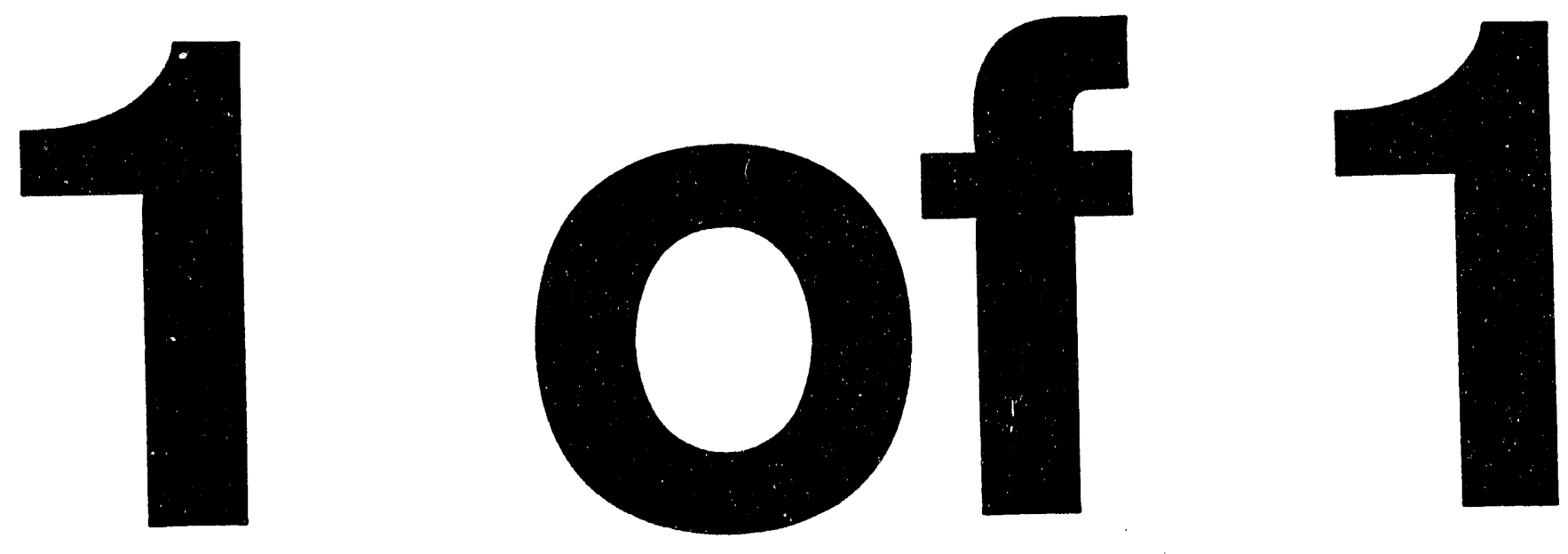


\section{Computational Science Applications in Manufacturing (CSAM) \\ Workshop Evaluation Report}

Kansas City Division

Jim Bradford,

Lester Dixon, and

Wesley Rutherford

KCP-613-5497

Published September 1994

Approved for public release; distribution is unlimited.

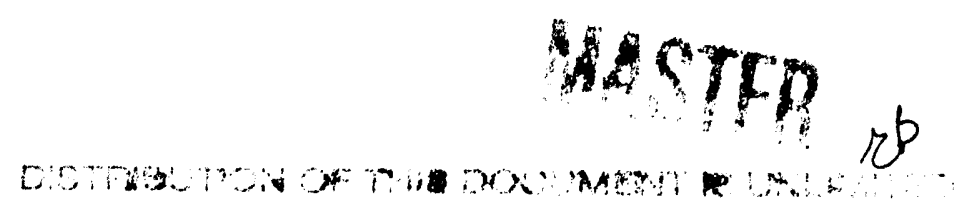

Prepared Under Contract Number DE-AC04-76-DP00613 for the United States Department of Energy 


\section{DISCLAIMER}

This report was prepared as an account of work sponsored by an agency of the United States Government. Neither the United States Government nor any agency thereof, nor any of their employees, makes any warranty, express or implied, or assumes any legal liability or responsibility for the accuracy, completeness, or usefulness of any information, apparatus, product, or process disclosed, or represents that its use would not infringe privately owned rights. Reference herein to any specific commercial product, process, or service by trade name, trademark, manufacturer, or otherwise, does not necessarily constitute or imply its endorsement, recommendation, or favoring by the United States Government or any agency thereof. The views and opinions of authors expressed herein do not necessarily state or reflect those of the United States Government or any agency thereot.

Printed in the United States of America.

This report has been reproduced from the best available copy.

Available to DOE and DOE contractors from the Office of Scientific and Technical Information, P. O. Box 62, Oak Ridge, Tennessee 37831; prices available from (615) 576-8401, FTS 626-8401.

Available to the public from the National Technical Information Service, U. S. Department of Commerce, 5285 Port Royal Rd., Springfield, Virginia 22161.

Copyright 1994 by AlliedSignal Inc. The Government is granted for itself and others acting on its behalf a paid-up, nonexclusive, irrevocable worldwide license in this data to reproduce, prepare derivative works, and perform publicly and display publicly.

A prime contractor with the United States Department of Energy under Contract Number DE-ACO4-78-DP00613.
AlliedSignal Inc. Kansas City Division P.O. Box 419159 Kansas Clty, Missouri 64141-6159 


\begin{abstract}
The Computational Science Applications in Manufacturing (CSAM) workshop is a program designed to expose and train high school students in the techniques used in computational science as they pertain to manufacturing. This effort was sponsored by the AlliedSignal Inc., Kansas City Division (KCD)* in cooperation with the Department of Energy (DOE) and their initiative to support education with respect to the advances in technology.
\end{abstract}

*Operated for the United States Department of Energy under Contract No. DE-ACO4-76-DP00613.

-Copyright AlliedSignal Inc., 1994 
COMPUTATIONAL SCIENCE APPLICATIONS IN MANUFACTURING (CSAM) WORKSHOP EVALUATION REPORT

Jim Bradford, Lester Dixon, and Wesley Rutherford

Published September 1994

A public report of information on a computational science workshop for high school students. 


\section{Contents}

1 Introduction 2

2 The Workshop 3

2.1 Week One $($ July $18-22) \ldots \ldots \ldots$

2.2 Week Two (July $25-29) \ldots \ldots \ldots$

2.3 Week Three (August 1-5) ............. 5

3 The Assessment and Evaluation 6

3.1 The Students .................... 6

3.2 The Workshop . . . . . . . . . . . . . . . 7

3.3 Discussions With Students And Teachers . . . . . . . . . 8

4 Conclusion 9

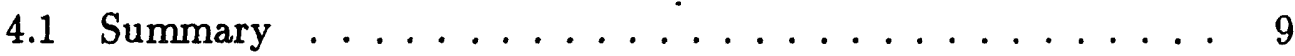

4.2 Recommendations . . . . . . . . . . . . . . 9

5 Appendix A 11

5.1 The Workshop Goals and Schedule . . . . . . . . . . 12

6 Appendix B $\quad 15$

6.1 Pre-Workshop Questionnaire . . . . . . . . . . . 16

6.2 Post-Workshop Questionnaire . . . . . . . . . . 17 


\section{Introduction}

A pilot project was developed at AlliedSignal Inc., Kansas City Division (KCD) in cooperation with the United States Department of Energy (DOE) to support their initiative in support of education in high school with respect to the advances in technology. This project consisted of a three week workshop for high school students. The objectives of this workshop were to expose and train the students in how:

1) mathematics, computer programs, and computer-aided design are used in manufacturing;

2) different types of problems require different kinds of computing power, such as personal computers (PCs), workstations, and supercomputers;

3) mathematics and computer programs are employed in the "black box" software that computers execute; and

4) computational science techniques are important in manufacturing.

The requirements for student participation were:

1) completion of at least mathematics courses in algebra two and trigonometry;

2) knowledge of a computer programming language (preferably);

3) returning as a high school student; and

4) United States citizenship.

A geographically diverse group of students was desired, that is students from urban, suburban, and rural areas. To that end, high schools in the Greater Kansas City area were asked to select students and sponsoring teachers. A limit of five students was allowed. However, one of the students selected was unable to attend, leaving only four students for the workshop. The sessions were held Monday through Friday, from 8:00 AM to 4:00 PM. See Appendix A for the outline of the workshop. Students were asked to keep notes on their daily impressions of the workshop. 


\section{The Workshop}

\subsection{Week One (July 18 - 22)}

The students were given a Pre-Workshop Questionnaire to fill out (see Appendix $\mathrm{B}$ for the results) on Monday morning, followed by a welcome by the manager of Human Resources Planning and Development. Next they received some high level training on the Silicon Graphics, Inc. (SGI) workstations.

A two day course on FORTRAN programming was presented to the students, which covered input/output (I/O), loops, arrays, subroutines, functions, etc. Next, the students were given a mathematics review which covered equations of lines, slopes, and basic trigonometric functions. This included a discussion on the interrelationships among the Pythagorean theorem, the distance formula, the equation of a cirçle, and the trigonometric identity $\sin ^{2} \theta+\cos ^{2} \theta=1$. The laws of sines and cosines were reviewed, and the students wrote a FORTRAN program using the law of cosines to determine the angle opposite a given side.

The students went on a tour of the Test Laboratory where they saw stress testing and qualitative analysis of materials and chemical and water sample testing. They also went to the area where recycling and environmentally safe cleaning are carried out.

For their next programming assignment, the students were given a circle of a certain radius. They had to calculate the points on the circumference so that it could be machined to a given tolerance. They also were required to calculate both the theoretical and approximate perimeters and compare their results. The mathematics required to accomplish this was discussed, and the students developed a FORTRAN program to generate the required results. They then used a plotting program to display the circle with the generated points.

The students went on a tour of the Flexible Manufacturing System (FMS) to see how the machines operated that would be used later to make their parts.

Next they were given a description of a part that was something like an airfoil (see Figure 1). Points on the perimeter had to be calculated so that the part could be machined to a given tolerance. The theoretical and approximate perimeters also had to be calculated and compared. The mathematics 


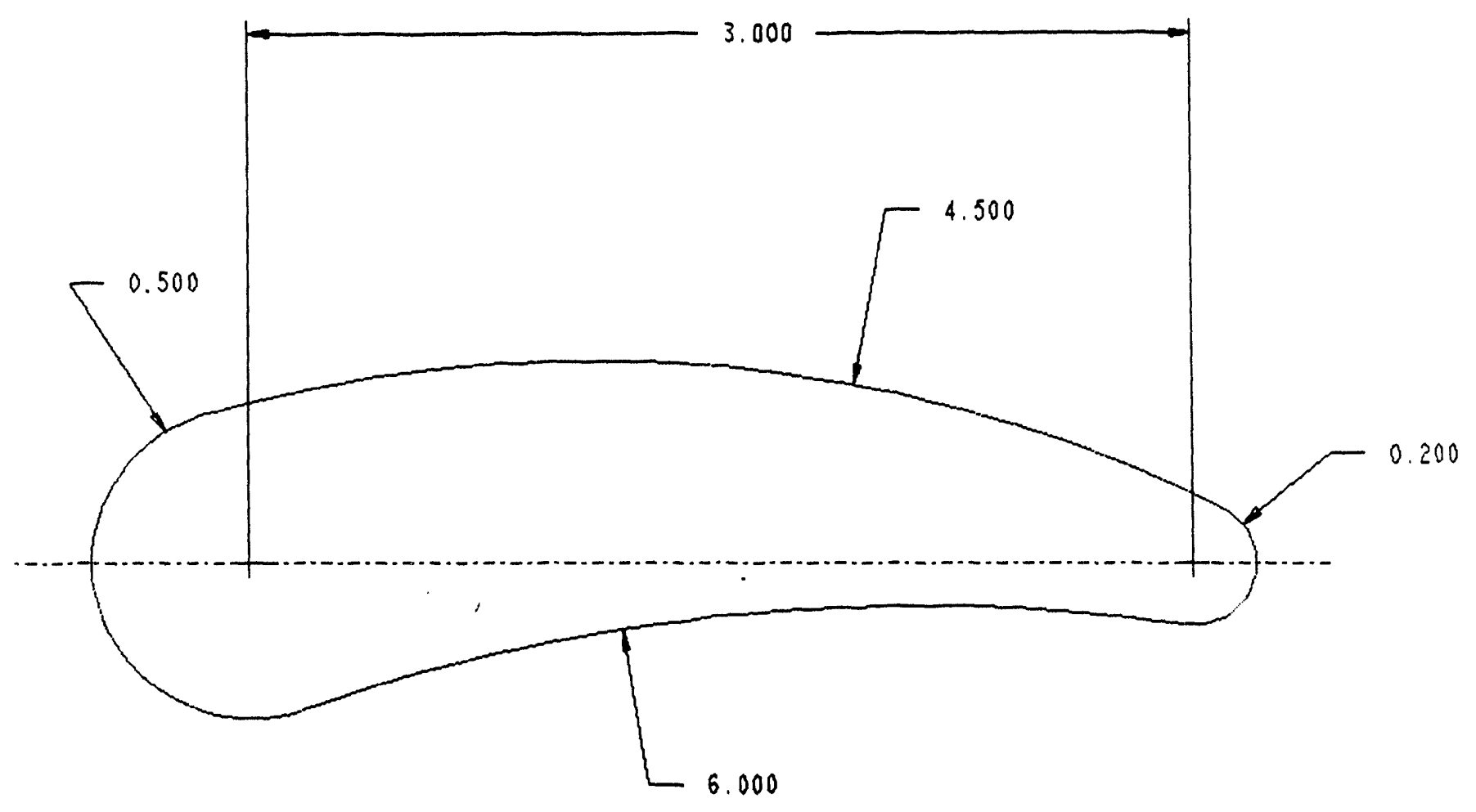

Figure 1: "airfoil"

necessary to accomplish this task was developed in detail. The development of the FORTRAN program was started but continued into the next week.

\subsection{Week Two (July 25 - 29)}

After the programming was completed, the students plotted the generated data points of the "airfoil" and wrote these data points to a floppy disk to give to a numerical control $(\mathrm{N} / \mathrm{C})$ analyst. The machine instructions were then generated to machine the part.

The students were given more mathematics review: matrices and determinants an vector analysis. They were required to write FORTRAN programs 
and subroutines to calculate the dot and cross products of two vectors and to determine the angle between them. This was followed by a review of the binomial theorem.

A presentation was given to the students on numerical control (N/C) and how it would be used in machining their "airfoil." Then the students went on a tour of the FMS to see their "airfoils" machined.

The students began working with Pro/ENGINEER Computer Aided Design software package (Pro/E) on the SGI workstations on Wednesday afternoon. (This continued into the third week.)

The students were given mathematics and computational science demonstrations that included:

1) Bezier curves and how they are used to define curves (e.g., airfoils) and surfaces for parts;

2) barycentric coordinates for points, lines, triangles, tetrahedra, and n-simplexes;

3) parametric curves and an example of an ellipse with a normal offset for a cutter radius;

4) how to map squares and triangles to form surface patches for parts;

5) a finite difference equation for rocket travel to the moon; and

6 ) the calculation of a dot product for vectors of length five-billion so that they could compare the performance of the Cray computer verses the SGI workstation.

\subsection{Week Three (August 1 - 5)}

The students were taken on a tour of the stereolithography area, after which a presentation on the various types of modeling, such as wireframe, hiddenline, and parametric, was given them. This was followed by more extensive training on Pro/E where they were shown how to model and assemble parts.

They also were given a demonstration of the electrical design system on an Intergraph workstation. 
The students were taken on a tour of the data center. There they were shown some of the various computers that KCD operates, including the Cray computer, and were given a discussion on their maintenance.

On the final day of the workshop the parents and sponsoring teachers of the students were invited to a recognition program during which the students gave a brief talk on their impressions of the workshop and how they benefited from it. They were presented with certificates and the machined "airfoil" for which they had generated the contour points.

Afterwards the parents and teachers were given demonstrations by the students on some of the things they had learned. A discussion by several of the workshop instructors and the parents and teachers was held. Topics discussed were how the workshop could be inproved and expanded so that other schools and students could benefit by it.

\section{The Assessment and Evaluation}

\subsection{The Students}

The students completed an application form indicating the mathematics and computer programming languages backgrounds. One of the students had taken only algebra two and trigonometry. Two had pre-calculus and one had calculus. In retrospect, the mathematics review was appropriate to provide all of the students with a refresher of familiar topics and exposure to new ones.

Although they all had some computer programming language exposure, none had any experience with FORTRAN. In addition, it became apparent that none of them had done any type of comprehensive computer programming such as was planned for them. Therefore, the two-day course on FORTRAN was essential.

Having the students write computer programs and subroutines to do the mathematics proved to be very beneficial for them to gain deeper insight into the mathematics. It also helped them to see more clearly the relationship of mathematics and programming to real world applications. Furthermore, actually seeing their "airfoil" machined helped the students realize how these disciplines tie together.

Although some of the students said that they had drafting experience, the 
exposure to Pro/E on a SGI workstation was a new and exciting adventure for them.

Tours of the various departments of the facility enhanced the students overall understanding and exposure to the interrelationship of the various fields and disciplines and the necessity for teamwork.

Presentations and discussions seemed to give the students a change of pace. They were very beneficial in providing the students with some broader exposure to the various disciplines, individually as well as together, in manufacturing applications.

The ability of the students to rapidly master the material provided quite a challenge. In many instances, they completed their tasks much sooner than had been anticipated. As a result, they were able to delve more deeply into some of the subject matter than had originally been planned and were able to cover more material.

\subsection{The Workshop}

In the welcome and orientation, attention was given to explaining:

1) the objectives of the program;

2) the time the program operates;

3) the layout of the facility, i.e. restrooms, etc.; and

4) the dress, safety, security, and other general regulations.

The basic structure of the program was to work with the students on their FORTRAN programming and the mathematics skills. These were used to write a computer program to generate the points to machine the assigned part to the designated specifications. Later they were taught how the same task could be accomplished using Pro/E on the SGI workstation.

This part of the project went exceptionally well. However, given the ease with which the students mastered their assignments, it became clear that additional tasks were needed for them to work on. Although additional material and work were given to them to do, future endeavors will require more tasks than had been planned for the workshop.

The Pro/E exposure proved to be both beneficial and exciting for the students. However, more time was spent with Pro/E than was warranted. It 
would have been more beneficial for the students to have been given more of a variety of projects requiring the programming of mathematics and science applications instead.

\subsection{Discussions With Students And Teachers}

Discussions were held with the students and the following are some of their comments.

- The program would be more effective if a teacher was invited to attend and to bring two students. This way the teachers, along with their students, could take what they learned back to their schools and teach it to others. The way the program was operated the students were able to profit, but what they learned only benefited themselves and not others.

- Junior high school students could also do the FORTRAN programming, but care should be taken not to use mathematics above their level.

- The support on the "airfoil" was instructive and beneficial. However, it would have been good to have been assigned another comparable problem to work as a team to solve alone, obtaining help only when requested.

- It would have been helpful and interesting if some compiter programming applications involving electronics had been given to them.

- The problems, the mathematics, and the FORTRAN programming that they were required to do helped them see the use of these disciplines in real world applications.

Below are some of the comments the teachers made concerning the program.

- They would like to receive some of the same training that the students had gotten.

- They would like to have access to some of AlliedSignal's computing power.

- They would like jo have a workshop on how to access the Internet.

- It would be beneficial if a network of teachers could be formed to work in conjunction with the Midwest Regional Supercomputing Center (MRSC). 
- It would be a good idea to have a bulletin board or library on the Internet, accessible by the teachers in the "network," containing projects that are instructive in the various aspects of computational science.

- It would be best if there were at least two teachers involved with the "computational science" program at each school. This is important for the mutual support and cross-fertilization necessary for a program like this to be successful.

\section{Conclusion}

\subsection{Summary}

The data from the Post-Workshop Questionnaires (see Appendix B) indicate that the pilot project, Computational Science Applications in Manufacturing (CSAM), achieved its objectives. The students were able to complete several FORTRAN programs that required the use of mathematical and technical knowledge. They were able to understand the need of mathematics and programming skills in order to accomplish the tasks that were assigned to them. And they all indicated that they enjoyed the experience.

It was clearly demonstrated that a program such as CSAM can provide valuable support to the educational needs of the community. In addition to this, one of the goals of the pilot project was to gain insight into how this concept could be improved and expanded to provide support for the community at large. The comments from the students and area teachers (see Section 3.3) provide excellent suggestions for improving future workshops.

\subsection{Recommendations}

Below are some recommendations that stand out based on the overall experience of the CSAM pilot project.

- The participants should be expanded to include teachers who are invited to bring two students.

- The projects should be broadened to include more subjects; for example, electronics and chemistry. 
- Plenty of problems should be "in the can" to address a variety of disciplines and the unanticipated speed at which many of the students accomplish them.

- At least one project should be assigned for the students to solve as a team, probably towards the end of the workshop.

- A library or bulletin board should be set up on the Internet consisting of problems and projects that teachers could access to have their students work on at their schools.

- Workshops should be held for teachers to learn how to access the Internet and what benefits they could derive from it.

- An association of teachers should be established to help plan and coordinate the direction of the CSAM program. One of the benefits for teachers belonging to this association could be permission to readily access the bulletin board and to obtain mentoring help from persons with the relevant expertise. 


\section{Appendix A}

The schedule of what was done in the workshop is included in this Appendix so that it can be seen in detail what was covered. 


\section{Appendix A}

AlliedSignal Kansas City Division 1994 Summer Educational Seminar

\section{"Computational Science Applications in Manufacturing"}

Week One Goal: $\quad$ Complete the mathematical description, programming and data creation necessary as input to KCD NC programming personnel to machine a simple 2D shape with a defined dimensional accuracy.

Monday,

July 18

10:00-12:00

$12: 00-1: 00$

$1: 00-2: 00$

2:00 - 3:40

$3: 40-4: 00$

Tuesday,

July 19

Wednesday, July 20

$$
\begin{array}{r}
12: 00-1: 00 \\
1: 00-3: 40
\end{array}
$$

$3: 40-4: 00$

$2: 00-1: 00$
$1: 00-2: 00$

2:00 - 3:40

3:40 - 4:00

8:00-12:00

Thursday, July 21

Friday, July 22
Math Review - Pythagorean theorem, trig review, Law of Sines and Law of Cosines

Lunch

Create FORTRAN program to calculate points on a circle maintaining a given level of accuracy

Welcome, Orientation \& Essentials

Introduction of CSAM Seminar

Computer Systems Orientation

Lunch

Computer Systems Orientation (cont.)

FORTRAN Programming I, introduction -variables, arrays, equations

Document Progress branching

Lunch

FORTRAN Programming 3, loops, functions

Math Review - points, lines, circles, slopes

Document Progress

Document Progress

Math review - Matrices, vectors, dot product, cross product

Lunch

Tour: Analytical Sciences Lab and "Barn"

Work on circle points program

Document Progress

"Introduction to NC Programming" presentation

Begin FORTRAN program calculating points of an "airfoil" profile

Lunch

Tour: Flexible Manufacturing System

Continue programming of "airfoil" points

Document Progress
8:00-12:00

$12: 00-1: 00$

1:00-2:00

2:00 - 3:40

3:40 - 4:00

8:00 - 9:00 9:00 - 12:00

12:00 - 1:00

1:00 - 2:00

2:00 - 3:40

3:40 - 4:00 
Week Two Goal: $\quad$ Complete mathematical description, programming and data creation necessary as input to KCD NC programming personnel to machine a selected more complex part.

Monday, 8:00-12:00 3D Math Review 1, 3D distance formula, equations

July 25 for parallelepiped, etc.

1:00 - 3:40 Continued programming of "airfoil" points

3:40 - 4:00 Document Progress

Tuesday, 8:00-12:00 Discussion of parametric modeling, computer

July 26

12:00 - 1:00 Lunch

1:00 - 2:30 3D Math Review 2, Bezier curves, parametric curves, surfaces, etc.

2:30 - 3:40 Intro. to using Pro/ENGINEER (Pro/E)

3:40 - 4:00 Document Progress

Wednesday, 8:00-9:30 Finite Element Analysis and animation

July 27

9:30-12:00 demonstration

12:00 - 1:00 Lunch

1:00 - 3:40 Work with Pro/E, Sketcher and Parts

3:40 - 4:00 Document Progress

Thursday, 8:00-12:00 Work with Pro/E, create Part models given basic

July 28

12:00 - 1:00 Lunch

1:00 - 2:00 Introduction to Stereolithography

- 2:00 - 3:40 Demonstrations of miscel. FORTRAN applications

3:40 - 4:00 Document Progress

Friday, 8:00-9:00 Discussion of NC Machining of "airfoil"

July $29 \quad 9: 00-12: 00$ Work with Pro/E, continue Part models

12:00 - 1:00 Lunch

1:00 - 2:00 Finite Element Analysis Demo

2:00 - 3:40 EDMA Demo: Hybrid Micro Circuit design

3:40 - 4:00 Document Progress 
Week Three Goal: Create "airfoil" Part in Pro/Engineer and have the part manufactured, either as a stereolithographic plastic prototype or machined from metal.

Monday, August 1

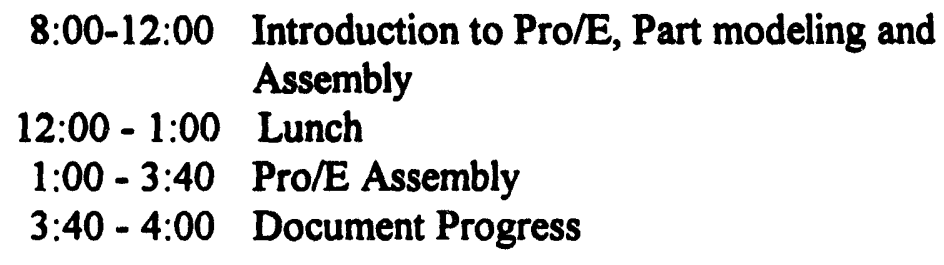

Tuesday, $\quad$ 8:00-12:00 Pro/E Assembly

August 2

12:00 - 1:00 Lunch

1:00 - 2:30 Tour: FMS to see "airfoils" machined

2:30 - 3:40 EDMA Demo: Printed Wiring Board design

3:40 - 4:00 Document Progress

Wednesday, $\quad 8: 00-12: 00$ Pro/E, Intro. to Advanced Curves and

August 3

12:00 - 1:00 Lunch

1:00 - 3:40 Pro/E, Advanced Curves and Surfaces

3:40 - 4:00 Document Progress

Thursday, $\quad 8: 00-12: 00 \quad$ Pro/E, Intro. to Drawings and Drawing

August 4

12:00 - 1:00 Lunch

1:00 - 2:00 Virus Modeling Presentation

2:00 - 3:40 Pro/E, Drawings

3:40 - 4:00 Document Progress

Friday, 8:00-10:30 Document FORTRAN programs, course August 5 notes, etc.

10:30-11:00 Tour: Central Computer Facility \#2, CRAY

11:00-12:00 Lunch

12:00 - 1:30 Management Presentation

1:30 - 4:00 Tour of SimCenter, Review of the Course, Discussion, Ideas for Improvements, Course Evaluation Forms 


\section{Appendix B}

The Pre-Workshop and Post-workshop questionnaires are summarized here. The frequency of the students' answers are given below the "scale-line," and their comments, where given, are in bold italics. 


\section{Appendix B}

\section{PRE-WORKSHOP QUESTIONNAIRE}

Please answer the questions below (add comments if you like).

\section{MATHEMATICS}

1 How do you rate your knowledge of trigonometry? Comments

\section{LOW}

HIGH

$\begin{array}{llllll}0 & 1 & 2 & 3 & 4 & 5 \\ & & & 1 & 3 & \end{array}$

2 How do you rate your knowledge of vectors?

Comments

$\begin{array}{llllll}0 & 1 & 2 & 3 & 4 & 5 \\ 1 & & & 2 & 1 & \end{array}$

\section{COMPUTING}

3 How do you rate your experience in computer usage for computational purposes?

Comments

4 How do you rate your experience in computer usage for documentation (i.e. word processing)?

Comments

5 How do you rate your experience in computer graphics?

\section{Comments}

6 How do you rate your knowledge of computer usage in manufacturing?

Comments

\section{GENERAL}

7 What are your expectations of this workshop?

Comments

Name: 
1994 POST-WORKSHOP QUESTIONNAIRE

Please answer the questions below (add comments if you like).

\section{MATHEMATICS}

1 Rate your improvement in mathematics skills as a result of the

LOW

HIGH mathematics presentations.

Comments

$\begin{array}{llllll}0 & 1 & 2 & 3 & 4 & 5\end{array}$

$\begin{array}{lll}1 & 1 & 2\end{array}$

2 Rate enhancement of your understanding of the relationship between mathematics and computer graphics.

Comments

\section{0}

$\begin{array}{llll}2 & 3 & 4 & 5\end{array}$

$1 \quad 1 \quad 2$

3 Rate enhancement of your understanding of the relationship between computational science and mathematics.

Comments

$\begin{array}{llllll}0 & 1 & 2 & 3 & 4 & 5\end{array}$

$4 \quad$ Rate benefit of the tours.

Comments

Comments

6 Rate quality of demonstrations.

Comments

$\begin{array}{llllll}0 & 1 & 2 & 3 & 4 & 5 \\ & & 1 & & 1 & 2\end{array}$

7 Was the mathematics presented challenging enough?

$(0=$ NO, $5=$ YES, $3=$ No Opinion)

Comments 
8 Was the mathematics presented understandable?

( 0 = NO, $5=$ YES, $3=$ No Opinion)

Comments

\section{PROGRAMMING}

9 Rate improvements to programs that you might write in the future where the improvement is due to mathematics presentations in the Computational Science Applications in Manufacturing project.

Comments

10 Rate enhancement of your understanding of programming concepts as a result of the mathematics presentations.

Comments

$\begin{array}{llllll}0 & 1 & 2 & 3 & 4 & 5\end{array}$

$1 \quad 1 \quad 2$

11 Was the programming presented challenging enough?

( $0=$ NO, $5=$ YES, $3=$ No Opinion)

Comments

12 Was the programming presented understandable?

( $0=$ NO, $5=$ YES, $3=$ No Opinion)

Comments

$\begin{array}{llllll}0 & 1 & 2 & 3 & 4 & 5\end{array}$

\section{GENERAL}

13 Was teamwork encouraged?

$(0=$ NO, $5=$ YES, $3=$ No Opinion $)$

Comments

The low marker said "more teamwork applications" were needed.

14 Rate the Computational Science Applications in Manufacturing program in terms of benefit to you in planning your own future. Comments 
15 Did you learn concepts to share with fellow students?

( $0=$ NO, $5=$ YES, 3=No Opinion)

Comments

16 Was the PRO ENGINEER exposure and exercise valuable to you? ( $0=$ NO, $5=$ YES, $3=$ No Opinion)

Comments

17 How was the overall length of the program (three weeks) suited for

$\begin{array}{llllll}0 & 1 & 2 & 3 & 4 & 5\end{array}$ the amount of material covered?

( $0=$ NO, $5=$ YES, $3=$ No Opinion)

Comments

One low marker said "more material was needed."

The other said "more time was needed" The question must be ambiguous.

18 Was 8 hours per day the optimal time for your learning and comprehension of the material?

( $0=\mathrm{NO}, 5=\mathrm{YES}, 3=$ No Opinion)

Comments 
22 Please state other example subject areas, (chemistry, physics, electronics, biochemistry, etc.) that would effectively focus the learning experience in Computational Science.

Comments

"electronics and physics"

23 How could the program be improved?

Comments

"Have electrical engineering aspects of Computational Science."

"More students and structure. Invite teacher to participate with two of their students."

24 In what ways could you have better prepared for this program?

Comments

(I could have) reviewed programming skills and mathematics.

Name: 

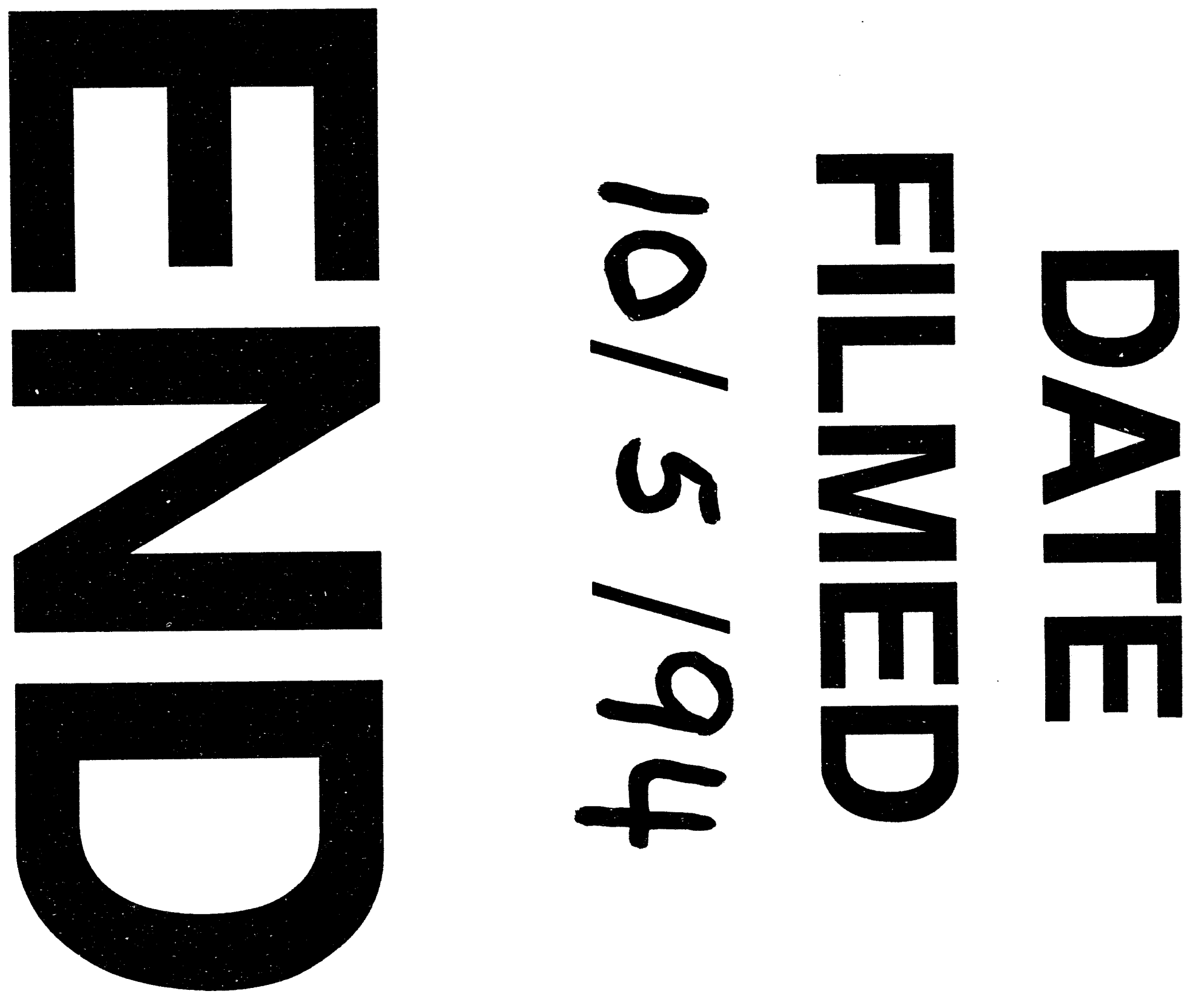